\title{
Customer experience quality surpasses NPS in correlation to financial performance, customer loyalty and customer satisfaction
}

Michele Bennett, PhD (michele.bennett@avanade.com

Anthony Molisani, PhD, MPH

Last Updated April 15, 2020

Supported by Avanade

\begin{abstract}
Customer loyalty and satisfaction drives business. For over a decade, NPS has been touted as the most important measure of loyalty and predictor of business growth, even as researchers have struggled to consistently prove the claim. Other measures of customer experience, loyalty and satisfaction have arisen that challenge the supremacy of NPS, even as hundreds of companies rely on NPS for its simplicity and promise of business growth. Measuring 1605 US-based customers of US publicly traded companies, this study has found that while NPS was positively and significantly correlated with customer loyalty, satisfaction, and financial performance, customer experience quality (CEQ) surpassed NPS in all three measures. The research also showed that CEQ was strongly correlated with NPS, suggesting that the two metrics are synergistic. The findings demonstrate that there is provable value in exploring metrics beyond NPS that companies may be missing and thereby limiting their growth and competitiveness.
\end{abstract}

\subsection{Introduction}

In 2001, Fredrick Reichheld (2003) found that Enterprise Rent-A-Car measured the customer experiences of their offices on two aspects, quality of experience and willingness to rent again, and only counted the highest ratings. Enterprise also found that the highest ratings correlated to profitability. From these learnings, the Net Promoter Score was created as a hallmark of customer loyalty (Reichheld, 2003), and has maintained its relevance to this day as hundreds of companies anxiously await and track their scores and those of their competitors (Gill, McCarthy, \& Grimmett, 2019).

However, over the years, researchers have struggled to reproduce the foundational results (Reichheld, 2003) showing NPS has a strong and positive impact on profitability and customer satisfaction (Eklof, Podkorytova, \& Malova, 2018; Kristensen, \& Esklldsen, 2014). Other metrics also have outperformed NPS in measuring loyalty and financial performance (Keiningham, Cooil, Wallin Andreassen, \& Aksoy, 2007). In addition, NPS ignores one of original premises of Enterprise's measures - quality of experience (Reichheld, 2003), and that quality of customer experience can be more consequential to a company's bottom line than NPS (Maklan \& Klaus, 2011; Mbama, 2018).

This research posits that NPS falls short of Reichheld's (2003) claim that it is the ultimate measure of customer loyalty and corporate growth, and that quality of experience is more impactful to customer satisfaction, loyalty, and financial performance. Companies relying on NPS as their primary customer metric are missing shortfalls in customer experiences that could be costing customers and profitability. 


\subsection{Literature Review}

\subsection{Net Promoter Score (NPS)}

Net Promoter Score (NPS) has long been held as one of the most important measurement of customer experience since its inception (Gill et al., 2019; Reichheld, 2003). Reichheld (2003) reported that the answer to the simple NPS question, "How likely is it that you would recommend [company $\mathrm{X}$ ] to a friend or colleague?" (p.49), was aligned with revenue growth, and is the most important metric that a business needs to track for success.

Over the years, other studies have sought to replicate the results of Reichheld (2003) with varying outcomes. For example, Keiningham et al. (2007) found that while NPS was correlated with revenue growth, however demonstrated that American Customer Satisfaction Index (ASCl) had a stronger correlation to revenue than NPS, putting the first crack into the superiority of NPS. ASCl is a multidimensional customer metric that includes customer satisfaction, customer expectations, perceived quality, perceived value, customer complaints, customer loyalty $(\mathrm{ASCl}, 2019)$ and is a similar definition to the one used in this research, which is also part of a larger study (Bennett \& Molisani, 2020).

In more recent studies, NPS has been shown to be a poor predictor of customer loyalty and satisfaction (Kristensen, \& Esklldsen, 2014), with the ASCl and European Performance Satisfaction Index (EPSI) have been found to be more reliable, trustworthy, and consistent measures of customer satisfaction and financial performance (Eklof et al., 2018; Kristensen, \& Esklldsen, 2014). Study authors caution against using NPS as a sole, or even the most critical tool for customer experience decisions.

\subsection{Customer Experience Quality (CEQ)}

Metrics such as ASCl and EPSI have become more prominent in the last few years, and define a multidimensional perspective of customer experience that includes constructs such as corporate image, customer expectations, perceived value, product quality, customer loyalty, and service quality (Eklof, Podkorytova, \& Malova, 2018; Kristensen, \& Esklldsen, 2014). The concept of Customer Experience Quality (CEQ) was developed to identify the most important attributes that align with customer loyalty, satisfaction and recommendations for relationship marketing and customer experience programs (Maklan \& Klaus, 2011). CEQ was defined by Maklan and Klaus (2011) as constructs around peace of mind (including expertise, process ease, convenience, relationships); outcome focus (including resultsfocused, innovation, past experience); moments of truth (flexibility, perceived risk, interpersonal skills, service quality); and product experience (freedom of choice, comparisons, and employee experience). The definition suited the banking industry as it evolved from products and services to experiences as the new competitive differentiator (Lemke, Clarke, and Wilson, 2011; Maklan \& Klaus, 2011).

Mbama (2018) used Maklan and Klaus (2011) and additional existing research (Gronholdt, 2019; Lemke et al., 2011) to define a definition of CEQ that could span industries and could measure financial performance. This research used the base assumptions and constructs of Mbama (2018) and defined CEQ as perceived value, convenience, functional quality, service quality, brand trust, employee-customer engagement, perceived usability, perceived risk, and technical innovation. The financial performance metric used in this study is market capitalization. Market capitalization (MC) has a strong and growing impact on the economy and is a recognized global metric of the value of a company (Pavone, 2019). 


\subsection{Research Methodology}

\subsection{Conceptual Model for Research}

Given the differences in findings across studies concerning NPS and its relationship with loyalty and satisfaction, differing definitions of customer experience, and inconsistent findings, this study extends the work of others (Gronholdt, 2019; Lemke et al. 2011; Maklan \& Klaus, 2011; Mbama, 2018), and examined the relationships between CEQ, NPS, CLY, CSAT, and financial performance.

An online questionnaire was used to collect data from 1605 US-based customers of US publicly traded companies in February 2019. The questionnaire asked participants about their perceptions and beliefs about the companies with which they do business or from which they purchase. The 54 questions were aligned with the factors positioned in Figure 1 below.

Figure 1: Conceptual Model for Research

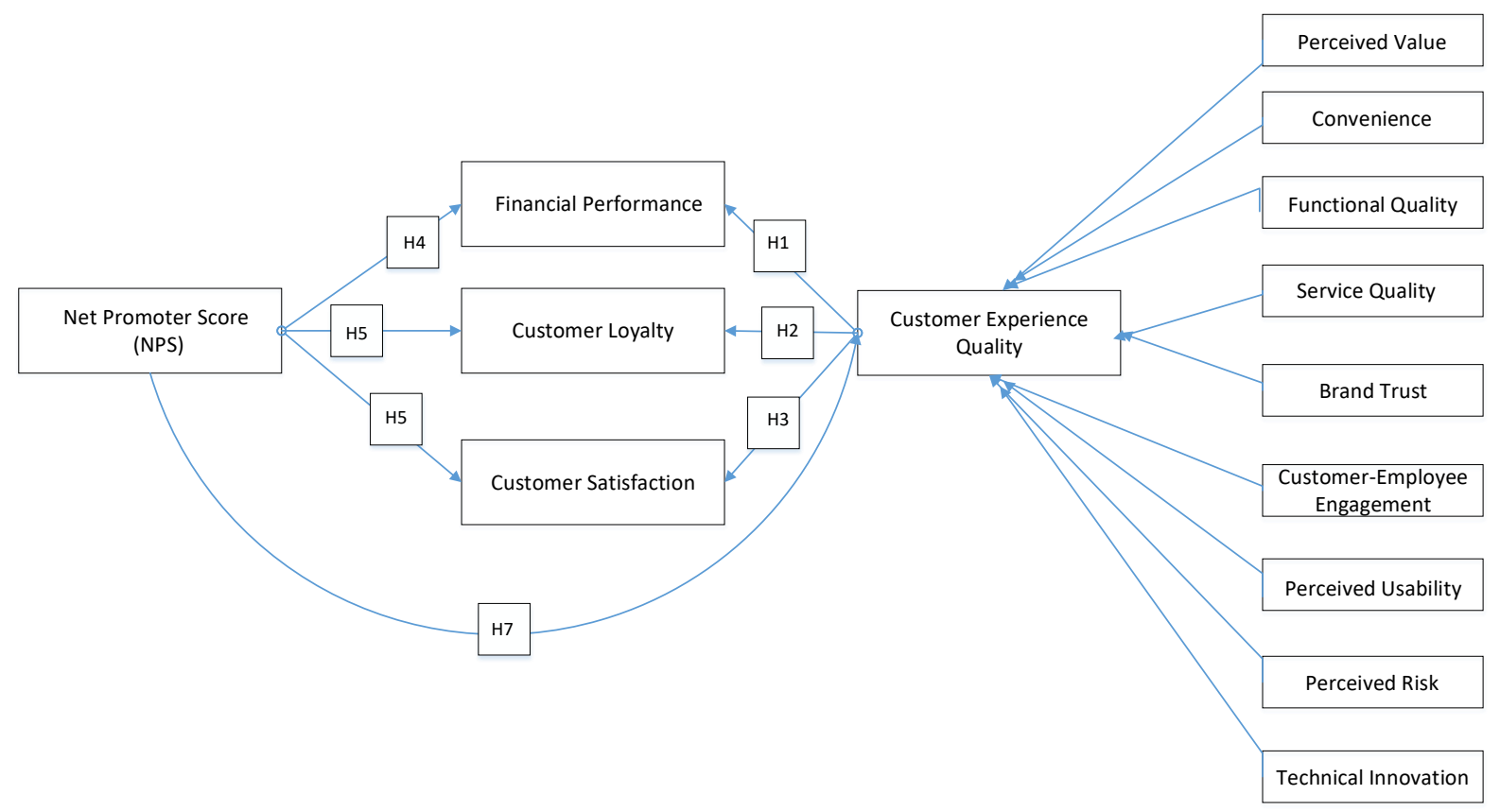

\subsection{Hypothesis Development}

Multi-dimensional customer experience metrics similar to CEQ have been shown to the correlated with financial performance (Gronholdt, 2019) as well as to customer satisfaction and loyalty (Mbama (2018) but not all studies have found connections between customer experience, loyalty, satisfaction, and financial performance (James, James, Babin, \& Parker, 2019).

Studies have also struggled to repeat Reichheld (2003) and NPS correlations with financial performance (Kristensen \& Eskildsen, 2014), and have shown disparity of findings with customer loyalty and satisfaction (Keiningham et al., 2007; Kristensen \& Eskilden, 2014) However, Mbama (2018) found NPS highly correlated with loyalty but not with satisfaction, differing from Reichheld (2003), and not with CEQ, aligning with Keingham et al. (2007). 
Therefore, this study seeks to provide more information to the body of knowledge surrounding customer experience concepts and financial performance.

\subsubsection{CEQ Hypotheses}

H1: There is a significant correlation between CEQ and MC

H2: There is a significant correlation between CEQ and CLY

H3: There is a significant correlation between CEQ and CSAT

\subsubsection{NPS Hypotheses}

H4: There is a significant correlation between NPS and MC

H5: There is a significant correlation between NPS and CLY

H6: There is a significant correlation between NPS and CSAT

\subsubsection{CEQ and NPS}

H7: There is a significant correlation between CEQ and NPS

\subsection{Research Findings}

The multi-dimensional CEQ was positively and significantly correlated with $\mathrm{MC}$ and stronger than the correlation between NPS and MC as shown in Table 1 . The study accepted $\mathrm{H} 1$ and $\mathrm{H} 4$ contrary to Mbama (2018) but in support of Gronholdt (2019).

CEQ was strongly and significantly correlated with CLY and CSAT, supporting Klaus and Maklan (2013), Maklan and Klaus (2011) and Mbama (2018), and the study accepted H2 and H3. NPS was also strongly and positively correlated with CLY and CSAT, and the study accepted H5 and H6. Mbama (2018) did not find a positive relationship between NPS and CSAT. but did between NPS and CLY. Kristensen and Eskildsen (2014) found NPS to have a weak and unreliable relationship between CSAT and CLY, and the relationship between CLY and CSAT was stronger with CEQ than with NPS. The results of this study align with Kristensen and Esklidsen (2014).

NPS and CEQ were strongly and positively correlated, which is counter to the findings of Keingham et al. (2007) and Mbama (2018). The study accepted H7, which is a novel finding.

Table 1: Correlation Results

\begin{tabular}{|l|l|l|}
\hline \multicolumn{1}{|c|}{ Hypothesis } & \multicolumn{1}{c|}{ Pearson Correlation } & \multicolumn{1}{c|}{ Outcome } \\
\hline $\begin{array}{l}\text { H1: There is a significant correlation } \\
\text { between CEQ and MC }\end{array}$ & $r=.118, p=.000^{* *}$ & Accept \\
\hline $\begin{array}{l}\text { H2: There is a significant correlation } \\
\text { between CEQ and CLY }\end{array}$ & $r=.841, p=.000^{* *}$ & Accept \\
\hline $\begin{array}{l}\text { H3: There is a significant correlation } \\
\text { between CEQ and CSAT }\end{array}$ & $\mathrm{r}=.781, \mathrm{p}=.000^{* *}$ & Accept \\
\hline $\begin{array}{l}\text { H4: There is a significant correlation } \\
\text { between NPS and MC }\end{array}$ & $\mathrm{r}=.086, \mathrm{p}=.000^{* *}$ & Accept \\
\hline
\end{tabular}




\begin{tabular}{|l|l|l|}
\hline \multicolumn{1}{|c|}{ Hypothesis } & \multicolumn{1}{|c|}{ Pearson Correlation } & \multicolumn{1}{c|}{ Outcome } \\
\hline $\begin{array}{l}\text { H5: There is a significant correlation } \\
\text { between NPS and CLY }\end{array}$ & $\mathrm{r}=.799, \mathrm{p}=.000^{* *}$ & Accept \\
\hline $\begin{array}{l}\text { H6: } \text { There is a significant correlation } \\
\text { between NPS and CSAT }\end{array}$ & $\mathrm{r}=.697, \mathrm{p}=.000^{* *}$ & Accept \\
\hline $\begin{array}{l}\text { H7: } \text { There is a significant correlation } \\
\text { between CEQ and NPS }\end{array}$ & $\mathrm{r}=.761, \mathrm{p}=.000^{* *}$ & Accept \\
\hline
\end{tabular}

*significant at $p<=.05 ;{ }^{* *}$ significant at $p<=.01$

\subsection{Discussion and Implications}

\subsection{Customer Loyalty and Satisfaction}

In this study, CEQ and NPS were both positively and significantly correlated with CLY and CSAT. The difference between the correlation between CEQ and CLY $(r=.841, p=.000)$ was $5.12 \%$ stronger than the correlation between NPS and CLY $(r=.799, p=.000)$. Mbama (2018) also found a stronger correlation between CEQ and CLY than between NPS and CLY, with a difference of $22.9 \%$. The difference between the correlation between CEQ and CSAT $(r=.781, p=.000)$ and NPS and CSAT $(r=$ $.697, p=.000$ ) was $100.37 \%$. Mbama (2018) found a much stronger correlation between CEQ and CSAT than between NPS and CSAT as well, with a difference of $105.15 \%$.

The results of this study provide additional evidence that NPS is not the only "one number you need to grow" (Reichheld, 2003, p46) when measuring customer loyalty and satisfaction, and a multidimensional metric that includes emotional, attitudinal, and quality-based factors is needed (Gao, Merelo-Polo, \& Sese, 2019; Gronholdt, 2019; Keiningham et al., 2019; Mbama, 2018) to capture the sum of a customer's experience with a company's products and services.

\subsection{Financial Performance}

The correlation between CEQ and MC $(r=.118, p=.000)$ is $31.37 \%$ stronger than the correlation between NPS and MC $(r=.086, p=.000)$. Gronholdt (2019) found a similar outcome of multidimensional CX and financial performance. This study confirmed the original premise of Reichheld (2003) and the positive impact of NPS on company growth but revealed a more impactful metric in CEQ than NPS that companies need to consider.

\subsection{Conclusion}

This research confirmed that NPS remains an important metric of customer loyalty, satisfaction, and company financial performance. However, NPS is not the most important metric a company needs to rely on as proclaimed by Reichheld (2003) and that measuring the quality of customer experiences can mean stronger loyalty, satisfaction, business performance, and competitiveness. In addition, NPS does not provide insight into the areas of customer experience to improve to increase scores (Fisher \& Kordupleski, 2018), so organizations are left with costly trial and error that may not just cost customers but unknowingly make experiences worse. CEQ provides multiple avenues for improving experiences, which can each be measured separately so companies can knowingly focus on the most impactful areas.

This study and others have proven that CEQ provides be an enormous advantage over NPS, especially in customer satisfaction and financial performance. Companies must look beyond NPS to ensure that their experiences are not just keeping customers but realizing their expectations in business value. 


\section{References}

American Customer Satisfaction Index (ASCI). (2019). ASCl benchmark. Retrieved from https://www.theacsi.org/products-and-services/industrywide/acsi-benchmark

Bennett M., \& Molisani, A. (2020). Defining customer experience and measuring its impact on financial performance of US publicly traded companies. SocArXIV, 1-26. doi: 10.31235/osf.io/mzepq

Dootson, P., Beatson, A., \& Drennan, J. (2016). Financial institutions using social media: Do customers perceive value? International Journal of Bank Marketing, 34(1). 9-36. doi: /10.1108/IJBM-062014-0079

Eklof, J., Podkorytova, O., \& Malova, A., (2018). Linking customer satisfaction with financial performance: an empirical study of Scandinavian banks. Total Quality Management \& Business Excellence. doi: 10.1080/14783363.2018.1504621

Fisher, N. I., \& Kordupleski, R. E. (2018). Good and bad market research: A critical review of Net Promoter Score. Applied Stochastic Models in Business and industry, 35(1), 138-151. doi: 10.1002/asmb.2417

Gao, X., Merelo-Polo, I., \& Sese, J. (2019). Customer equity drivers, customer experience quality, and customer profitability in banking services: The moderating role of social influence. Journal of Service Research. doi: 10.1177/1094670519856119

Gill, L., McCarthy, V., \& Grimmett, D. (2019). Voice of the customer: Creating client centered cultures in accounting firms for retaining clients and increasing profitability. Journal of Accounting, Business and Management, 26(2), 46-58. doi: 10.31966/jabminternational.v26i2.412

Gronholdt, L. (2019). Digital customer experience: An emerging theme in customer service excellence. Newsletter on Consumer Behavior 31, 2-10.

James, K.W., James, H., Babin, B. J., \& Parker, J. M. (2019). Is customer satisfaction really a catch-all? The discrepancy between financial performance and survey results. Journal of Managerial Issues, $31(2), 137-150$.

Keiningham, T., Askoy, L., Bruce, H. L., Cadet, F., Clennell, N., Hodgkinson, I. R., \& Kearney, T. (2019). Customer experience driven business model innovation. Journal of Business Research. Advance online publication. doi: 10.1016/j.jbusres.2019.08.003

Keiningham, T. L., Cooil, B., Wallin Andreassen, T., \& Aksoy, L. (2007). A longitudinal examination of net promoter and firm revenue growth. Journal of Marketing, 71, 39-51. Retrieved from https://pdfs.semanticscholar.org/dfe0/4f3d83fee37a617d9cacfebc331605dc4bfc.pdf

Kristensen, K., \& Eskildsen, J. (2014). Is the NPS a trustworthy performance measure? The TQM Journal, 26(2), 202-214. doi: 10.1108/TQM-03-2011-0021.

Lemke, F., Clark, M., \& Wilson, H. (2011). Customer experience quality: An exploration in business and consumer contexts using repertory grid technique. Journal of the Academy of Marketing Science 39(6):846-869. doi: 10.1007/s11747-010-0219-0 
Maklan, S. \& Klaus, P. (2011) Customer Experience: Are we measuring the right things. International Journal of Market Research, 53(6), 771-792.

Pavone, P. (2019). Market capitalization and financial variables: Evidence from Italian listed companies. International Journal of Academic Research Business and Social Sciences, 9(3), 1356-1371

Reichheld, F. F. (2003). The one number you need to grow. Harvard Business Review, 81, 46-54. 